Eur. J. Clin. Chem. Clin. Biochem.

Vol. 31, 1993, pp. 103-106

(C) 1993 Walter de Gruyter \& Co. Berlin $\cdot$ New York

\title{
Glutamine and Glutamate in Ascitic Fluid of Dogs
}

\author{
By J. Hirschberger ${ }^{1}, M$. Goldberg ${ }^{2}$ and Ursula G. Sauer ${ }^{1}$ \\ 1 I. Medizinische Tierklinik \\ 2 Institut für Tierphysiologie
}

University of Munich, Federal Republic of Germany

(Received March 26/October 18, 1992)

Summary: The amino acid pattern in the ascites of 79 dogs was examined. The concentration of glutamine in neoplastic ascites is significantly lower than in cardial effusions. In contrast, glutamate is significantly higher in neoplastic ascites than in cardial ascites. Using an arbitrary discrimination value of 0.28 for the glutamate/glutamine ratio, purulent or cardial ascites are easily differentiated, with a sensitivity of $100 \%$ and a specificity of $94 \%$. The differentiation is very distinct, with no overlap between the group of patients with liver cirrhosis on the one hand and the groups of patients with purulent peritonitis, heart failure, or malignant ascites on the other hand. There was no diagnostically usable correlation between the concentrations of the other 20 amino acids and the underlying causes of ascites formation.

\section{Introduction}

The examination of body effusions contributes to the aetiological diagnosis of diseases. In a search for quantities that differentiate neoplastic, hepatogenic, cardial and infected ascites, we measured 22 amino acids in the body effusions of dogs. Decades ago, amino acids were measured in body effusions with semiquantitative methods $(1,2)$. Paper partition chromatography does not allow determination of the absolute concentration of amino acids; the intensity of the ninhydrin colour reaction has been graded from one to ten against an arbitrary colour standard (1). Ion exchange methods did not separate glutamine from serine (2). In the present study, body fluids were examined with the modern quantitative method of HPLC. The measurement of amino acids in aetiologically different ascitic fluids of animals with exact quantitative methods has not been published before.

\section{Materials and Methods}

The ascitic fluids of 79 dogs were analysed. Cardial ascites was found in 32 , neoplastic ascites in 13, ascites caused by a ruptured haemangioendothelioma in 14, purulent ascites in nine, ascites caused by enteral hypoproteinaemia in five, ascites caused by renal hypoproteinaemia in four and cirrhotic ascites in two cases. The causes of these effusions were diagnosed by necropsy or by an extended clinical control of the patients. The ascitic fluid was obtained by abdominal paracentesis under sonographic guide and centrifuged at $1570 \mathrm{~g}$ for 10 minutes. The supernatant was stored at $-18^{\circ} \mathrm{C}$ until high performance liquid chromatography (HPLC) was performed (3). The recovery rate of standard amino acids (Sigma Chemie, Germany) added to the samples before work-up was $>95 \%$. No decreases of amino acid concentrations were observed in the ascitic fluids after two months of storage. Twenty two amino acids were measured (tab. 1). In the statistical examination the Mann-Whitney-Utest was used; a p-value lower than 0.01 was considered significant.

\section{Results}

Table 1 shows the results for the analysis of samples from the patients with heart failure, abdominal neoplasia, ruptured haemangioendothelioma with abdominal bleeding, purulent peritonitis, enteral and renal hypoproteinaemia and liver cirrhosis. The mean values of 22 amino acids and the total numbers of the patients are shown for the different diseases. The glutamine concentration of $389.97 \pm 147.75 \mu \mathrm{mol} / \mathrm{l}$ in an ascitic effusion caused by heart failure (tab. 2) is nearly twice as high as the glutamine concentration 
Tab. 1. Amino acid concentration $(\mu \mathrm{mol} /)$ in ascites of dogs suffering from cardiac insufficiency, neoplasia, ruptured haemangioendothelioma, purulent peritonitis, enteral hypoproteinaemia, renal hypoproteinaemia or liver cirrhosis. In addition, amino acid concentration in plasma (5) of healthy dogs is given (n.d. = not done).

\begin{tabular}{|c|c|c|c|c|c|c|c|c|}
\hline Amino acids & $\begin{array}{l}\text { Cardiac } \\
\text { insuf- } \\
\text { ficiency } \\
\mathrm{n}=32\end{array}$ & $\begin{array}{l}\text { Neo- } \\
\text { plasia } \\
\mathrm{n}=13\end{array}$ & $\begin{array}{l}\text { Ruptured } \\
\text { haemangio- } \\
\text { endo- } \\
\text { thelioma } \\
n=14\end{array}$ & $\begin{array}{l}\text { Purulent } \\
\text { peri- } \\
\text { tonitis } \\
\mathrm{n}=9\end{array}$ & $\begin{array}{l}\text { Enteral } \\
\text { hypo- } \\
\text { protein- } \\
\text { aemia } \\
n=5\end{array}$ & $\begin{array}{l}\text { Renal } \\
\text { hypo- } \\
\text { protein- } \\
\text { aemia } \\
n=4\end{array}$ & $\begin{array}{l}\text { 'Liver } \\
\text { cirrhosis }\end{array}$ & Plasma \\
\hline Glutamate & 46.21 & 112.12 & 98.49 & 275.08 & 8.96 & 52.88 & 6.80 & 27.70 \\
\hline Glutamine & 389.97 & 203.79 & 336.07 & 174.56 & 169.02 & 195.89 & 441.80 & 967.30 \\
\hline Phosphoserine & 1.95 & 1.93 & 1.69 & 1.69 & 1.66 & 3.31 & 1.93 & n.d. \\
\hline Aspartate & 275.45 & 291.31 & 279.35 & 335.87 & 298.73 & 308.84 & 289.67 & 10.70 \\
\hline Asparagine & 33.75 & 25.81 & 31.58 & 22.66 & 17.32 & 18.49 & 19.15 & 25.80 \\
\hline Serine & 95.77 & 75.72 & 101.70 & 86.74 & 35.81 & 45.64 & 63.48 & 116.80 \\
\hline Phosphoethanolamine & 5.08 & 16.02 & 2.26 & 4.72 & 6.17 & 15.02 & 8.58 & n.d. \\
\hline Glycine & 196.07 & 174.50 & 213.97 & 253.16 & 91.69 & 134.59 & 108.85 & 190.80 \\
\hline Threonine & 164.86 & 121.61 & 146.01 & 147.63 & 97.93 & 99.73 & 68.97 & 191.80 \\
\hline Histidine & 107.81 & 99.10 & 136.90 & 145.90 & 47.77 & 61.00 & 112.35 & 82.50 \\
\hline Alanine & 301.90 & 225.62 & 343.96 & 328.57 & 127.04 & 106.01 & 160.92 & 435.80 \\
\hline Taurine & 117.69 & 150.47 & 156.06 & 253.59 & 42.46 & 163.05 & 64.80 & 128.40 \\
\hline Arginine & 80.80 & 58.12 & 94.09 & 103.52 & 42.10 & 49.46 & 46.63 & 137.70 \\
\hline Tyrosine & 40.20 & 40.53 & 49.83 & 118.01 & 15.77 & 29.23 & 61.96 & 48.40 \\
\hline Valine & 146.79 & 106.70 & 155.71 & 256.88 & 78.38 & 78.79 & 84.85 & 211.60 \\
\hline Methionine & 39.75 & 25.85 & 28.44 & 67.13 & 16.99 & 31.40 & 22.76 & 58.20 \\
\hline Tryptophan & 41.34 & 43.66 & 72.24 & 104.52 & 10.22 & 38.05 & 25.56 & 65.30 \\
\hline Phenylalanine & 57.50 & 55.48 & 75.97 & 88.49 & 21.54 & 53.61 & 95.91. & 59.60 \\
\hline Isoleucine & 73.71 & 53.07 & 83.32 & 108.91 & 37.48 & 50.45 & 22.90 & 79.80 \\
\hline Leucine & 126.33 & 90.17 & 149.42 & 408.43 & 54.46 & 96.28 & 56.90 & 156.20 \\
\hline Ornithine & 7.67 & 6.00 & 6.81 & 16.51 & 4.17 & 5.34 & 3.45 & 18.60 \\
\hline Lysine & 57.46 & 48.74 & 66.64 & 95.03 & 27.88 & 35.50 & 37.47 & 190.30 \\
\hline
\end{tabular}

Tab. 2. Glutamate and glutamine concentration ( $\mu \mathrm{mol} / \mathrm{l})$ in ascites of dogs suffering from cardiac insufficiency, neoplasia, ruptured haemangioendothelioma, purulent peritonitis, enteral hypoproteinaemia, renal hypoproteinaemia or liver cirrhosis.

\begin{tabular}{lrrr}
\hline & \multicolumn{1}{l}{ Glutamate } & Glutamine & n \\
\hline Cardiac insufficiency & $46.21 \pm 51.52$ & $389.98 \pm 147.75$ & 32 \\
Neoplasia & $112.12 \pm 122.05$ & $203.79 \pm 85.89$ & 13 \\
Ruptured haemangioendothelioma & $98.49 \pm 184.31$ & $336.07 \pm 119.48$ & 14 \\
Purulent peritonitis & $275.08 \pm 291.28$ & $174.56 \pm 130.47$ & 9 \\
Enteral hypoproteinaemia & $8.96 \pm 169.02 \pm 98.71$ & 5 \\
Renal hypoproteinaemia & $52.88 \pm 57.40$ & $195.89 \pm 53.37$ & 4 \\
Liver cirrhosis & $6.80 \pm(0.84-12.76)$ & $441.80 \pm(232.18-651.42)$ & 2 \\
\hline
\end{tabular}

of $203.79 \pm 85.79 \mu \mathrm{mol} / \mathrm{l}$ in an ascitic effusion caused by neoplasia. The values differ significantly $(p<0.01)$. The opposite relationship is observed for glutamate; the glutamate concentration in neoplastic ascites is twice as high as in cardial ascites. In purulent abdominal effusions (tab. 2) the glutamine concentration of $174.56 \pm 130.47 \mu \mathrm{mol} / \mathrm{l}$ is relatively low compared with cardial and neoplastic ascites, and the glutamate concentration of $275.08 \pm 291.28 \mu \mathrm{mol} / \mathrm{l}$ is the highest one measured in the seven groups of ascites causes. Only in purulent ascites is the mean value of the glu/gln ratio $(5.66 \pm 10.73)$ greater one (fig. 1). The difference between the glu/gln ratio of purulent, cardial or malignant ascites and that of cirrhotic ascites is much more obvious. There is no overlap between the group of cirrhotic ascites and the group including purulent, cardial and malignant ascites.
The sum of the mean values of glutamine and glutamate is lower in the groups with malignancy and renal or enteral hypoproteinaemia (tab. 2) than in the other groups. The mean concentrations of the amino acids are less in dogs suffering from enteral hypoproteinaemia than in patients with renal hypoproteinaemia. In the two cases with liver cirrhosis the glutamine concentration is relatively high and the glutamate concentration is low.

\section{Discussion}

Glutamine is the amino acid with the highest concentration in plasma. It is the major nutriment for most cells including tumour cells (4) and it serves as a transport form for ammonia. The reference values for 


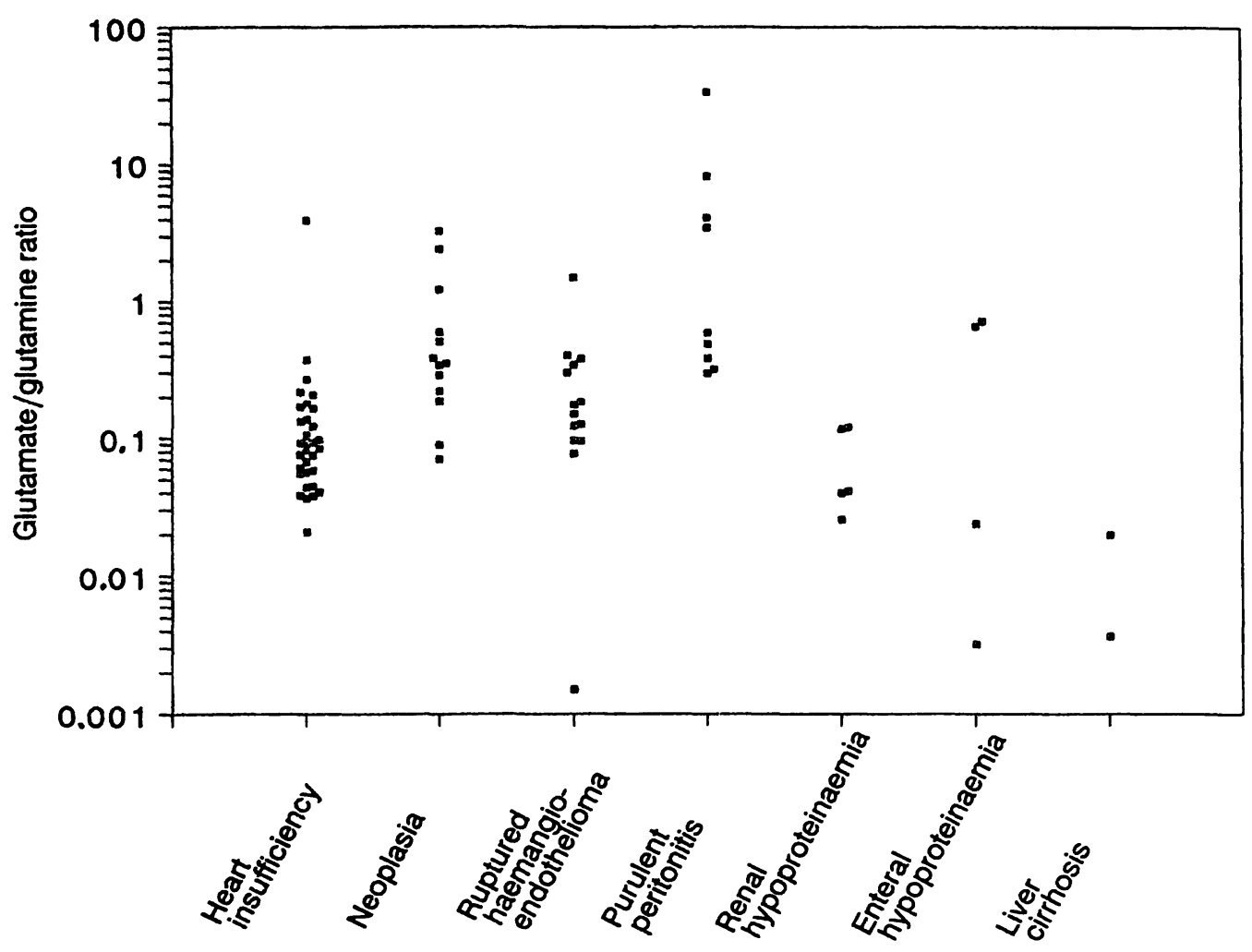

Fig. 1. Glutamate/glutamine ratio (logarithmic scale) of abdominal effusions of dogs suffering from cardiac insufficiency, neoplasia, ruptured haemangioendothelioma, purulent peritonitis, renal hypoproteinaemia, enteral hypoproteinaemia and liver cirrhosis.

glutamine in the plasma of dogs have been reported as $967.3 \pm 53.1 \mu \mathrm{mol} / \mathrm{l}(5)$ and as $824 \pm 74 \mu \mathrm{mol} / 1$ (6). The glutamate concentration has been reported as $27.7 \mu \mathrm{mol} / 1$ (5) and as $31 \pm 3 \mu \mathrm{mol} / 1$ (6). Very similar reference values have been reported for humans.

A certain relationship between the glutamine concentration of the ascitic fluid and the glutamine of the plasma might be expected, so that a decrease of the plasma concentration may lead to a decrease of the ascitic concentration. Plasma glutamine is known to be markedly decreased in catabolic diseases (7). Thus, in catabolic diseases with body effusions, the glutamine concentration may also be decreased in the ascitic fluid.

Glutamine and glutamate are easily interconverted, so the sum of both amino acids was also considered. In malignancy and in renal or enteral hypoproteinaemia, the sum of glutamine and glutamate in the ascites is lower than in cardial or purulent ascites. This may be due to enforced catabolism in malignancy and protein loss in renal and enteral hypoproteinaemia.

In cardial and cirrhotic ascites the glutamine concentration is clearly bigher than in malignant or purulent ascites (tab. 2). The glutamate concentration is inversely related to that of glutamine. The glutamate concentration is higher in malignant and purulent effusions and lower in cardial and cirrhotic effusions. This may be due to incomplete deamidation of glutamine to glutamate as a result of hypoxia (8), and the secretion of glutamate by tumour cells $(8,9)$. Glutamine can also be converted into glutamate by macrophages and fibroblasts (10). The glutamate concentration in the effusion is low in cardial effusions (46.21 $\pm 51.52 \mu \mathrm{mol} / \mathrm{l})$, higher in malignant effusions $(112 \pm 122.05 \mu \mathrm{mol} / \mathrm{l})$ and markedly higher in purulent ascites $(275.08 \pm 291.28 \mu \mathrm{mol} / \mathrm{l})$. This increase of glutamate concentrations is paralleled by the increase of lactate dehydrogenase activity in abdominal effusions in the same diseases (11). Plasma and the most forms of body effusions contain more glutamine than glutamate. One exception is the purulent ascites (fig. 1). This may be explained by the fact that the purulent ascites contains an enormous number of cells, mostly neutrophilic granulocytes. This ascitic medium is hypoxic, and the oxygenation of the abdominal effusion only takes place at the serous membranes. Glutamine is incompletely deamidated to glutamate. Therefore, the mean value of the glu/gln ratio is greater than one only in purulent ascites (fig. 1). The glu/gln ratio seems to be a quantity which significantly discriminates cardial from infectious ascites. There is only a small overlap between samples from patients with cardial effusions and patients with pu- 
rulent abdominal effusions, as can be seen from figure 1. Fixing empirically a discrimination value of 0.28 for the glu/gln ratio, all patients with purulent ascites have a glu/gln ratio above 0.28 and 30 cases of the 32 cases with heart failure have a ratio below 0.28 . The sensitivity of the glu/gln ratio for distinguishing between cardial and purulent ascites is $100 \%$ and the specificity is $94 \%$. The predictive value of a positive result for diagnosis of an infectious effusion is $82 \%$. The predictive value of a negative result for ruling out an infectious effusion is $100 \%$.

Unfortunately the group of cirrhotic ascites contains only two dogs. Compared with humans, liver cirrhosis is relatively uncommon in companion animals. A larger group of patients suffering from liver cirrhosis is required to test whether the glutamate concentration and the glu/gln ratio are acceptable quantities for differentiating cirrhotic ascites from other causes. It is expected that an increase of the glu/gln ratio in the ascites of a patient suffering from liver cirrhosis

\section{References}

1. Sandler, M. (1956) Amino acid levels in pleural exudates. Thorax 11,60-64.

2. Knauff, H. G., Selmair, H. \& Zickgraf, H. (1960) Die freien Aminosäuren in Ascites- und Pleurapunktaten. Hoppe-Seylers Z. Physiol. Chem. 318, 73-81.

3. Godel, H., Graser, T., Földi, P., Pfaender P. \& Fürst, P. (1984) Measurement of free amino acids in human biological fluids by High-Performance Liquid Chromatography. J. Chromatogr. 297, 49-61.

4. Fischer, J. E. \& Chance, W. T. (1990) Total parenteral nutrition, glutamine, and tumor growth. J. Parenteral Enteral Nutrition $14,86 \mathrm{~S}-89 \mathrm{~S}$.

5. Strombeck, D. R. \& Rogers, Q. (1978) Plasma amino acid concentrations in dogs with hepatic disease. J. Am. Vet. Med. Assoc. 173, 93-96.

6. Rutgers, Carolien, Stradley, R. P. \& Rogers, W. A. (1987) Plasma amino acid analysis in dogs with experimentally induced hepatocellular and obstructive jaundice. Am. J. Vet. Res. 48, 696-702.

7. Smith, R. J. \& Wilmore, D. W. (1990) Glutamine nutrition and requirements. J. Parenteral Enteral Nutrition 14, 94S99S. would indicate an infection of the ascitic fluid. The possible value of an increased glu/gln ratio as an early marker of the dangerous spontaneous bacterial peritonitis should be investigated. Spontaneous bacterial peritonitis is a spontaneous infection of preexisting chronic ascites. The microbiological evaluation of the abdominal fluid is the most important test for this condition, but culturing of bacteria always lasts some days and produces many false negative results. Clinicians are therefore investigating values, such as nucleated cell count, lactate dehydrogenase activity, fluid $\mathrm{pH}$ and total protein as early indicators of an infection of body fluids (12). For this reason the glu/gln ratio would have a special importance in human medicine.

Of the 22 amino acids tested, only glutamine and glutamate seem to be of interest for the laboratory examination of body effusions. There was no correlation between the concentration of any of the other 20 amino acids in the abdominal effusion and the underlying cause of ascites formation.

8. Ollenschlaeger, G., Karner, J., Karner-Hanusch, J., Jansen, S., Schindler, J. \& Roth, E. (1989) Plasma glutamate - a prognostic marker of cancer and of other immunodeficiency syndromes? Scand. J. Clin. Lab. Invest. 49, 773-777.

9. Marquez, J., Sanchez-Jimenez, F., Medina, M. A., Quesada, A. R. \& de Castro, I. N. (1989) Nitrogen metabolism in tumor bearing mice. Arch. Biochem. Biophys. 268, 667675.

10. Caldwell, M. D. (1989) Local glutamine metabolism in wounds and inflammation. Metabolism 38, Suppl. 1, $34-39$.

11. Hirschberger, J. \& Sauer, Ursula G. (1991) Klinisch-chemische Untersuchung von Körperhöhlenergüssen. Tierärztl. Prax. 19, $431-434$.

12. El-Touny, M., Osmạn, L., Abd-el-Hamid, T. \& Sabbour, M. S. (1989) Re-evaluation of the value of ascitic fluid $\mathrm{pH}$, lactate dehydrogenase and total proteins in the diagnosis of spontaneous bacterial peritonitis (SBP). J. Trop. Med. Hyg. 92, 6-9.

Dr. J. Hirschberger

I. Med. Tierklinik

Veterinärstraße 13

W-8000 München

Bundesrepublik Deutschland 